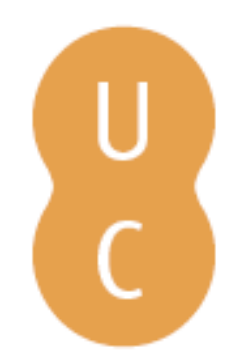

\title{
pombalina
}

\section{Discursos distintos para concepções diferentes da fé cristã}

Autor(es): Rebelo, António Ribeiro

Publicado por: Centro de Estudos Clássicos e Humanísticos; Imprensa da Universidade

URL

persistente: URI:http://hdl.handle.net/10316.2/31163

DOI: $\quad$ DOI:http://dx.doi.org/10.14195/978-989-8281-98-2_2

Accessed : $\quad$ 26-Apr-2023 16:34:30

A navegação consulta e descarregamento dos títulos inseridos nas Bibliotecas Digitais UC Digitalis, UC Pombalina e UC Impactum, pressupõem a aceitação plena e sem reservas dos Termos e Condições de Uso destas Bibliotecas Digitais, disponíveis em https://digitalis.uc.pt/pt-pt/termos.

Conforme exposto nos referidos Termos e Condições de Uso, o descarregamento de títulos de acesso restrito requer uma licença válida de autorização devendo o utilizador aceder ao(s) documento(s) a partir de um endereço de IP da instituição detentora da supramencionada licença.

Ao utilizador é apenas permitido o descarregamento para uso pessoal, pelo que o emprego do(s) título(s) descarregado(s) para outro fim, designadamente comercial, carece de autorização do respetivo autor ou editor da obra.

Na medida em que todas as obras da UC Digitalis se encontram protegidas pelo Código do Direito de Autor e Direitos Conexos e demais legislação aplicável, toda a cópia, parcial ou total, deste documento, nos casos em que é legalmente admitida, deverá conter ou fazer-se acompanhar por este aviso.

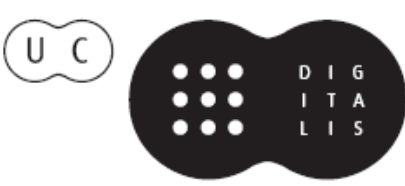


Colecção Autores Gregos e Latinos SérIe Ensaios

\section{Nair Castro Soares Margarida Miranda Carlota Miranda Urbano}

(Coord.)

HOMO ELOQVENS HOMO POLITICVS

A retórica e a CONSTRUÇão da CIDAdE NA IdAdE MÉdia E NO RENASCIMENTO 


\title{
DisCURSOS DISTINTOS PARA CONCEPÇÓES DIFERENTES DA FÉ CRISTÁ
}

\author{
António Ribeiro Rebelo
}


Perante a mesma situação, a Fé do cristão medieval pode conduzir a leituras divergentes dos factos, suscitadas por uma vivência multímoda dos princípios evangélicos que tem implicaçóes significativas no seu modo de agir e de pensar. Esta multiplicidade interpretativa, que os textos sagrados e as obras das grandes figuras da História da Igreja permitem, reflecte-se igualmente nos textos literários, designadamente na historiografia e na hagiografia. Os discursos são os elementos mais exemplificativos, porque caracterizam, de forma directa, a maneira de pensar e a forma de agir das personagens.

A este propósito, propomo-nos analisar detidamente os discursos de D. Fernando e D. Henrique proferidos por ocasiáo da conquista de Tânger e registados na biografia latina de D. Fernando - o Martyrium et Gesta Infantis Domini Fernandi... (doravante Martyrium et Gesta...). São discursos literários extensos, que não se encontram atestados nem em Fr. João Álvares, nem em Rui de Pina. No âmbito da obra, constituem o núcleo historiográfico:

o $4^{\circ}$ discurso (de D. Henrique): lin. 330-353;

o $5^{\circ}$ discurso (de D. Fernando): lin. 416-446;

o $6^{\circ}$ discurso (de D. Henrique): lin. 446-452;

o $8^{\circ}$ discurso (de D. Henrique): lin. 476-494;

e o $9^{\circ}$ discurso (de D. Fernando): lin. 496-514. 
Estes discursos incidem essencialmente na discussão da posição confrangedora em que os soldados portugueses se encontram depois dos reveses na tentativa da conquista de Tânger, no Verâo e Outono de 1437. Sobretudo as alocuçóes que precedem a rendição, durante as quais são pesadas as vantagens e desvantagens, bem como os termos do armistício, são elementos retóricos de uma forte densidade dramática que exploram a trágica situação em que os Portugueses se haviam colocado. Mais que quaisquer outros passos, estes discursos permitem moldar, à maneira de Tito Lívio $^{1}$, um retrato dinâmico dos dois protagonistas do Martyrium et Gesta..., D. Henrique e D. Fernando, evidenciando, de forma bem clara, forças de tensão opostas.

Estas peças de notável oratória exprimem ideais aparentemente antagónicos porque enfatizam maneiras diferentes de sentir e viver o cristianismo, fruto de interpretaçóes diversas dos sinais divinos ou dos sinais dos tempos: se uma das atitudes radica na humildade e, por conseguinte, no sentimento de o ser humano se considerar indigno de uma intervenção divina, aliado à responsabilidade cristâ, perante Deus, pela salvação eterna dos homens que a Pátria lhes confiou, a outra

${ }^{1}$ A finalidade estilística do discurso em Tito Lívio prende-se não só com o retrato psicológico das personagens, mas também com a exposição de uma determinada situação na sua globalidade. Além disso, os discursos serviam para imprimir maior vivacidade ao texto, através do equilíbrio estabelecido com as partes essencialmente descritivas e narrativas. Cf. Bayet, Jean (1965), Littérature latine, Paris, p. 244. 
baseia-se no secular espírito de cruzada, numa fé firme e determinada no auxílio divino - uma fé que, como diz o Evangelho, é capaz de fazer mover montanhas -, aliada a uma esperança indefectível na conquista da salvação eterna em caso de morte.

$\mathrm{O}$ facto de não se encontrarem registados nos cronistas da época leva a crer que os discursos do Martyrium et Gesta... são fictícios, à maneira dos historiógrafos clássicos ${ }^{2}$, ainda que possamos afiançar que o biógrafo fernandino recorre a outras fontes que os outros cronistas não registam ${ }^{3}$. A bem dizer, a influência clássica evidenciada pela intertextualidade literária, a um nível macro-estrutural, é confirmada por uma intertextualidade linguística, com particular incidência nas características semânticas, assimiladas pelo idiolecto do autor, e nas sintácticas. Efectivamente, é ao longo deste núcleo central, de natureza essencialmente historiográfica que se concentram as citaçôes de autores clássicos ${ }^{4}$. Este processo foi também muito utilizado por

${ }^{2}$ Vd. Bayet, Jean (1965), Littérature latine, Paris, p. 168: A l'exemple des Grecs, les historiens latins s'étaient mis à composer des discours, même fictifs, en tout cas outrepassant leur documentation réelle, qu'ils prêtaient aux personnages principaux en des circonstances notables, et qui leur permettaient d'exposer de façon vivante soit l'ensemble d'une situation, soit les fondements d'une entreprise.

3 Efectivamente, o biógrafo anónimo não circunscreveu as suas fontes à matéria desenvolvida no Trautado de Fr. Joáo Álvares. Terá usado outro tipo de informaçôes, escritas ou orais, às quais o redactor da Crónica de El-Rei D. Duarte terá recorrido - independentemente de Rui de Pina se ter ou náo servido de materiais de Zurara ou de Fernáo Lopes.

${ }^{4} \mathrm{O}$ facto de o autor aliar narraçôes puramente historiográficas 
Rui de Pina, sobretudo nas crónicas que lhe são mais genuínas: a de D. Afonso V e a de D. João $\mathrm{II}^{5}$.

$\mathrm{Na}$ Antiguidade Latina, era o discurso que caracterizava o melhor estilo de Salústio ${ }^{6}$. Era também o discurso um processo emblemático da historiografia liviana: na totalidade da obra que chegou até nós, contam-se quatro centenas de discursos!

Conjugam-se, pois, nos discursos do Martyrium et Gesta..., os principais traços distintivos dos historiadores latinos da Antiguidade. As próprias características linguísticas parecem ser o reflexo disso ${ }^{7}$. No Martyrium et Gesta... revelam uma arguta análise psicológica à maneira de Tácito. O historiador latino privilegiava o sentido pragmático dos factos. Como esse pragmatismo é exercido pelos agentes ou protagonistas

a uma obra de cariz essencialmente hagiográfico poderia explicar-se mediante o intuito de conferir maior verosimilhança a um texto que se enquadrava indubitavelmente num género que, pelos excessos que, por vezes, eram cometidos, corria o risco de cair no descrédito ou na rotina de tópicos, de milagres, que acabavam por ser considerados lugares-comuns. Todavia, julgamos que as razóes que poderão ter influído na elaboraçáo de um discurso narrativo com um peso historiográfico tão relevante numa obra de cariz predominantemente hagiográfico serão sobretudo de ordem literária.

${ }^{5} \mathrm{Vd}$. e. g. a caracterização das referidas crónicas em Gomes, R. Costa (1993), "Rui de Pina" in Giulia Lanciani e Giuseppe Tavani (org. e coord.), Dicionário da Literatura Medieval Galega e Portuguesa, Lisboa,.

${ }^{6}$ Cf. Bayet, Jean (1965), Littérature latine, Paris, p. 173: "Aussi a-t-il trouvé dans la forme traditionnelle du discours son véritable mode d'expression [...]".

${ }^{7}$ Cf. e.g. Paratore, Ettore (1987) História da Literatura Latina, trad. de Manuel Losa, SJ, Lisboa, pp. 736 sq, a propósito do estilo de Tácito. 
da História, a sua prioridade consiste em perscrutar a alma, os pensamentos e os sentimentos dessas pessoas, expondo ao público as secretas forças impulsoras das suas acçóes. A primazia do discurso é concedida ao retrato da alma, que explica todos os procedimentos do indivíduo. É que o rumo da História é determinado pelas características psicológicas dos seus agentes e, por sua vez, os eventos brotam, com toda a naturalidade, do carácter das personagens históricas. Também o autor do Martyrium et Gesta... soube plasmar nos respectivos discursos as personalidades de D. Henrique e do Infante D. Fernando.

A intrepidez que D. Henrique evidencia nas diversas intervençóes ao longo do Martyrium et Gesta... (designadamente as lin. 331-333, 335, 337-338, 450-452 e 482-485), fundamentada, por sua vez, numa confiança absoluta na Divina Providência, enquadra-se no espírito do ideal de cavalaria, na tradição do miles Christi, que alia o fervor religioso ao ardor guerreiro ${ }^{8}$. Lembremos que, já na guerra de Ceuta, o jovem Infante manifestara estas características. No De Bello Septensi de Mateus de Pisano, D. João I ordena que ninguém desembarque antes de D. Henrique o ter feito9. É o jovem Infante, cioso de feitos gloriosos, a fim de poder ser armado cavaleiro, que deseja ser o primeiro a pisar as areias de Ceuta ${ }^{10}$.

${ }^{8}$ Cf. e.g. Livro dos Conselhos de El-Rei D. Duarte (fol. $131^{\mathrm{v}}$ e $132^{\mathrm{r}}$ ).

${ }^{9} \mathrm{Vd}$. BDVV, ms. $n^{\circ} 1$, fol. 35": "His dictis, imperauit uti omnes ad desiliendum se pararent, nibilominus nemo prius desiliret quam Henricum desilijsse uideret".

${ }^{10}$ Cf. Gomes Eanes de Zurara, Crónica da tomada de Ceuta, 
Não admira, pois, que deste miles Christi, a um tempo animado por um ardente proselitismo religioso e vibrante de um incontível entusiasmo na perspectiva de mais um feito bélico, sobressaia uma confiança absoluta e incondicional na Divina Providência. Assim se explica a citação bíblica dos dois livros dos Macabeus na lin. 333 do Martyrium et Gesta...: "Não é na quantidade de homens, mas na misericórdia divina que devemos esperar do Céu a vitória “ (Non in multitudine, sed in misericordia Dei de caelo speremus uictoriam), uma expressão composta a partir de dois passos bíblicos diferentes: 1Mcc 3.19 ("non in multitudine exercitus est uictoria belli, sed de caelo fortitudo est") e $2 \mathrm{Mcc}$ 15.8 ("adiutoria sibi facta de caelo et nunc sperarent ab Omnipotente adfuturam sibi uictoriam").

A resistência de Matatias e de seus cinco filhos, os Macabeus, entre os quais avultava Judas, passou para a tradição judaico-cristá como uma das principais referências de heroicidade veterotestamentária. $\mathrm{Na}$ literatura latina medieval, a citação explícita de $1 \mathrm{Mcc}$ $3.18-19^{11}$ ocorre, pela primeira vez, no famoso elogio

cap. 24. O mesmo autor, no cap. 71 desta crónica, confirma que as hostes do Navegador foram as primeiras a entrar na cidade.

${ }^{11}$ Contextualizemos este passo: Mas ao verem aquele exército que marchava contra eles, os companheiros disseram a Judas: "Como poderemos nós, tấo poucos, combater contra tão grande multidão, tanto mais que nos sentimos fracos por estarmos hoje ainda em jejum?”. Mas Judas respondeu: "É fácil que muitos venham a cair às mãos de poucos; para o Deus do céu não há diferença entre salvar com muitos ou com poucos, porque o triunfo de uma batalha não depende do número de soldados, mas da força que vem do céu" (Et ait Iudas: "Facile est concludi multos in manibus paucorum; et non est differentia in conspectu caeli liberare in multis 
dos Templários por S. Bernardo, o Liber Ad Milites Templi - De Laude Nouae Militiae, onde o abade de Claraval delineia a missáo e o espírito da nova cavalaria. A partir daí, é retomada na literatura de cruzadas e nas crónicas da reconquista:

Irrompem sobre os adversários, como se os inimigos fossem gado, e, ainda que sejam muito poucos, jamais temem a bárbara crueldade ou a numerosa multidão. Estão igualmente ensinados a não confiar nas suas próprias forças, mas a esperar a vitória do poder do Deus dos Exércitos, e nessa ordem de ideias acreditam ser extremamente fácil, segundo a expressão do Macabeu,

"que muitos venham a cair às mãos de poucos e que para o Deus do céu não há diferença entre salvar com muitos ou com poucos, porque o triunfo de uma batalha não depende do número de soldados, mas da força que vem do céu."

Isto eles têm experimentado também com muita frequência, a ponto de muitas vezes um único ter posto em fuga um milhar de homens e dois terem afugentado dez $m i l^{12}$.

aut in paucis, quoniam non in multitudine exercitus victoria belli, sed de caelo fortitudo est.).

${ }_{12}$ S. Bernardo, Liber Ad Milites Templi - De Laude Nouae Militiae, 4.8 , in J.-P. Migne, PL 182, pp. 921-940 ou Bernhard von Clairvaux (1990), Sämtliche Werke, lateinisch und deutsch (ed. Gerhard B. Winkler), Innsbruck: Irruunt in aduersarios, hostes uelut oues reputant, nequaquam, etsi paucissimi, uel saenam barbariem, uel numerosam multitudinem formidantes. Nouerunt siquidem non de suis praesumere uiribus, sed de uirtute Domini 
Antes de o biógrafo fernandino o adaptar ao seu texto, já o tópico do Livro dos Macabeus fora utilizado por D. João I antes da Batalha de Aljubarrota ${ }^{13}$ e a ele recorrera também D. Duarte, no seu Livro dos Conselhos: "[...] lembrandouos quantos catholicos prinçipes e outros da ley uelha, com muy pouca gente, uençerom grande multidom de jnfieis[...]".

O Mestre da Ordem de Cristo, sucessora da Ordem do Templo, tomava a sério o papel tradicional de miles Christi e a função de cruzada permanente contra os infiéis. Não admira, pois, que D. Henrique procurasse seguir à letra tudo quanto S. Bernardo prescrevia no seu Liber Ad Milites Templi, que passou a ser um verdadeiro decálogo para os cavaleiros templários. Daí que o Navegador estivesse pronto a dar a sua vida por Cristo. Efectivamente, do pormenor da referência à bula de cruzada (lin. 227) infere-se a remissão plenária dos pecados dos combatentes lusitanos, por si só razão suficiente para se advogar um futuro beatífico para todos quantos viessem a sofrer a morte na sequência de um

Sabaoth sperare uictoriam, cui nimirum facile esse confidunt, iuxta sententiam Macchabaei, concludi multos in manus paucorum, et non esse differentiam in conspectu Dei caeli liberare in multis, et in paucis, quia non in multitudine exercitus est uictoria belli, sed de caelo fortitudo est. Quod et frequentissime experti sunt, ita ut plerumque quasi persecutus sit unus mille, et duo fugarint decem millia.

${ }_{13}$ Fernáo Lopes faz alusão ao episódio do Macabeu nos capítulos 30, 41 e 48 da Primeira Parte da Crónica de D. João I (cf. Fernão Lopes (1977), Cronica del Rei Dom Joham I de boa memória $e$ dos Reis de Portugal o decimo, Parte Primeira escrita por Fernão Lopes. Reprodução fac-similada da edição do Arquivo Histórico Português (1915) preparada por Anselmo Braamcamp Freire. Prefácio por Luís F. Lindley Cintra, Lisboa). 
eventual desenlace fatal dos acontecimentos. E, no seu segundo discurso (lin. 446-452), D. Henrique admite mesmo a morte como fuga para a glória:

"É próprio de um espírito inteligente e ilustre aceitar ou preferir morrer uma só vez pela Fé a ter uma vida longa e morrer muitas vezes com o nome difamado. [...] está estabelecido que todo o homem morre uma só vez" (Ingenui et praeclari animi est liberius et melius pro fide semel mori, quam diu uiuere, saepius turpi nomine moriendo. [...] statutum enim est omni homini semel mori).

Muito particularmente nas lin. 447-449, integradas no discurso de D. Henrique, é a honra que está em causa. O Infante de Sagres invoca uma das maiores virtudes dos grandes heróis épicos e um dos grandes ideais da cavalaria: a salvaguarda da honra a todo o custo. O legado clássico encontra-se pejado de verdadeiros paradigmas de heroísmos deste jaez.

A atitude do Mestre da Ordem de Cristo era entendida outrora, à luz da mentalidade medieval e do ideal de cavalaria, como uma das maiores virtudes ${ }^{14}$. Os

14 Efectivamente, no De Bello Septensi, Mateus de Pisano comprova que este sentimento não era inédito. Quando a frota chegou a Ceuta, foi desmembrada por uma violentíssima tempestade. Reunidos os cerca de 250 vasos que constituíam a armada, D. João I sonda as intenções das suas tropas, inquirindo se sempre mantêm a disposição de atacar Ceuta ou se preferem avançar para outras bandas. São várias as opinióes. Os jovens Infantes, ansiosos por merecerem o grau de cavaleiro, preferem, já então, a honra da morte à ignomínia da escusa em se exporem aos perigos (Ideo prestare omnia ferre pericula quam ignominia notari, cui honesta mors est preferenda). Vd. BDVV, ms. $n^{\circ} 1$, fol. $32^{v}$. Cf. 
sentimentos que D. Henrique manifesta no Martyrium et Gesta... já ele os herdara de seu pai, como se pode constatar pela forma como as expressóes de D. Joáo I, vertidas por Fernão Lopes e Zurara, são aplicadas pelos cronistas latinos a D. Henrique. Eram mentalidades típicas de uma época influenciada pelo espírito de cavalaria, alimentada pela leitura das gloriosas proezas de Galaaz, o cavaleiro puro, e da demanda do Graal pelos míticos cavaleiros da Távola Redonda.

Porém, os ideais dos dois tipos de cavaleiro (secular e religioso) constituíam uma amálgama indissolúvel de sentimentos no espírito do Infante de Sagres. Um aspecto pressupunha o outro e esta combinação de sentimentos reflectia-se no modus agendi do Mestre da Ordem de Cristo.

É assim que o Infante D. Henrique explana aos seus homens as desvantagens que o armistício teria para Portugal e as consequências negativas da desonra pessoal com que cada um deles seria coberto para os anos vindouros. Onde os Portugueses desvalorizavam as implicaçôes morais e legais dos termos da rendição, dizendo que não tinham poderes para prometerem a troca de Ceuta (lin. 471), D. Henrique contrapunha que, apesar disso, se devia manter a palavra a todo o custo.

O Navegador colocava, por isso, a morte honrosa acima da vergonha da derrota, como se pode depreender das lin. 480 sqq: "Eu, pela minha parte, preferia dilatar

igualmente Gomes Eanes de Zurara, Crónica da tomada de Ceuta, cap. 61. 
o firm da guerra a cair nas mãos dos infiéis" (Ego ipse liberius optarem belli finem immorari quam in Infidelium manus incidere $)^{15}$. Em primeiro lugar, revela a nobreza do seu carácter e o sentido da honra e do dever. Em segundo lugar, confirma o que os nobres haviam alegado (nas lin. 248-250) para atribuírem o comando da expedição ao Infante de Sagres:

"o qual - nós bem o sabemos - teme mais a infâmia do que a morte e tem em maior conta a honra do que o seu bem-estar ou outras comodidades" (quem nouimus plus turpitudinem horrere quam mortem et plus ad honestatem quam ad salutem uel ad alia commoda expectare).

Já D. Fernando se revela mais realista e responsável nas intervençôes. A decisão de se entregar como refém em troca da libertação de seu amado irmão e dos seus homens, que viam nele um pai espiritual (lin. 26 sq) revela uma preocupação preponderantemente religiosa. O Infante Santo assume a atitude do pelicano e, qual alter Christus, oferece-se pela salvação espiritual daqueles seus filhos que correriam o risco de renegar a fé cristấ sob coacção, torturas e maus-tratos durante o duro cativeiro africano que os esperaria. Não o afligia apenas o perigo de ter que prestar contas a Deus pela

${ }^{15}$ Esta afirmação pode não parecer muito abonatória do carácter de D. Henrique, mas ela é passível de uma dupla interpretação e deve ser entendida na perspectiva do comentário sobre as lin. 449 sqq: "É, com efeito, amarga a fama que nos espera, se formos vencidos por estes câes" (Amara siquidem nobis sistit fama, si ab istis diuincimur canibus). 
perdição daqueles que lhe haviam sido confiados. $\mathrm{O}$ seu procedimento era coerente com a sua preocupação em resgatar os Cristãos cativos dos infiéis (Martyrium et Gesta... lin. 166-169). Jamais ele poderia consentir ser responsável por uma desgraça que ele próprio considerava táo atroz.

Há, portanto, uma diferença de perspectivas entre D. Fernando e D. Henrique. Enquanto D. Fernando se preocupa sobretudo com a salvação das almas, para D. Henrique é antes a honra que é posta em causa, a reputação, a opiniáo pública, o julgamento do povo e da Corte, perante o vexame de uma derrota desonrosa, quando regressar à Pátria de mãos vazias e com a promessa de restituir Ceuta, que seu pai havia conquistado ${ }^{16}$. Sendo ele o chefe da expedição é sobre a sua pessoa que recairia a responsabilidade da derrota. É por isso que entre a morte pela Fé e a desonra ele prefere a primeira, que lhe assegurava a eternidade e só aumentava os méritos do seu renome. É, pois, compreensível que ele tente convencer os outros companheiros a seguirem esta soluçáo. Mas, por outro lado, D. Henrique evoca, nesta ocasião, a efemeridade da vida humana ( lin. 451 sq): "está estabelecido que todo o homem morre uma só vez" (statutum enim est omni homini semel mori). Estas palavras, citadas de $\mathrm{Hbr} 9.27$ ("statutum enim est hominibus semel mori”), com as quais ele procura

16 D. Henrique assume aqui uma atitude consentânea não apenas com o espírito de cavalaria, mas também com o carácter do herói épico que só vê a sua glória eternizada se os seus feitos forem celebrados pelos poetas. 
animar as suas tropas e que são o culminar de todo um discurso em que o Navegador evidencia a sua coragem, abnegação e determinação em lutar até à morte, se necessário for, produzem, todavia, o efeito contrário entre as suas gentes. Como estes náo tinham sobre os ombros a responsabilidade militar, política e histórica de D. Henrique, a possível desonra também não os incomodava, por ficar diluída no anonimato dos seus modestos cargos.

Por sua vez, os capitães portugueses invocam um argumento ao qual o Infante D. Fernando náo ficaria insensível: o da responsabilidade dos graduados perante Deus, se, na sequência de uma má decisão, os seus subalternos viessem a cair nas máos dos inimigos e renegassem a sua fé ${ }^{17}$.

$\mathrm{Na}$ resposta a um dos discursos do comandante-chefe da missão, os soldados lusitanos davam antes ouvidos às razóes de D. Fernando e encontraram argumentos adicionais de natureza soteriológica, para inclinar o Príncipe Constante à solução do armistício (lin. 464-465): "Nosso Senhor, vencedor da morte, não veio, de facto, para salvar as pedras, mas antes para salvar os homens" (Dominus Noster, destructor mortis, non reuera uenit saluare lapides, immo uerius homines).

Como é evidente, o autor fez aqui uma adaptação consciente do propósito de Cristo, transmitido pelo

${ }^{17}$ Ao narrar os factos desta maneira, o autor acaba por ilibar também o Infante D. Henrique da responsabilidade na futura morte do irmáo, porque foi este que assim quis que se fizesse. Ao mesmo tempo, salvaguarda a honra do comandante, uma vez que D. Henrique pretendia lutar até à morte. 
Evangelho de S. Lucas: "non ueni uocare iustos, sed peccatores" (Lc 5.32). No texto de Lucas, a oposição está condicionada aos seres humanos: os justos e os pecadores. No contexto de Tânger, é um argumento de maior peso, porque opóe os seres humanos às pedras (i. e. Ceuta). $\mathrm{Na}$ espiritualidade cristâ, esta questão não chegava a pôr-se. Colocar seres inanimados no mesmo plano ou até acima dos seres animados e racionais, seria subverter por completo o projecto divino da Criação, uma vez que os elementos foram colocados ao serviço do Homem e não ao inverso. O argumento aqui exposto é, pois, inabalável e $\mathrm{D}$. Fernando não deixa de ser sensível a este aspecto.

De um modo geral, os discursos em si são literariamente bem elaborados e estão conformes à retórica e oratória da época. A belicosa intervenção do Infante D. Henrique (lin. 330-353), por exemplo, em que o Navegador, incansável e inconformado, tenta dar novo alento às suas tropas, apelando ao brio e à intrepidez dos soldados de Cristo, para que se entreguem inteiramente e de forma denodada à luta, não cumpre todos os itens da retórica clássica, ainda que seja este o trecho que concentra mais citaçóes de autores clássicos. $\mathrm{Na}$ verdade, a probatio é desenvolvida com recurso a inúmeras auctoritates clássicas (Séneca, por três vezes, e ainda Virgílio, Lucano e Cícero), para reforçar o impacto argumentativo. Todavia, a acumulação de tantos exemplos deste genus artificiale da probatio, deixa transparecer o desespero do Navegador na tentativa de convencer o seu auditório. 
O biógrafo latino recorre à autoridade de Séneca, para reforçar algumas das afirmaçóes do discurso de D. Henrique, emprestando-lhe o vigor expressivo que é característico das máximas e provérbios. Séneca e Cícero são os autores clássicos mais citados ao longo do Martyrium et Gesta... E não admira, pois eram muito populares na corte de Avis. D. Henrique inspirase muito em Séneca e em Virgílio para encorajar e animar os Portugueses, abatidos pela inferioridade numérica. Esgotados os artifícios retóricos, o jovem príncipe recorre a grandes autoridades literárias e lança mão de todos os argumentos, para incentivar as tropas desmoralizadas. Sobretudo o primeiro discurso henriquino é de profundo sabor clássico: além do filósofo cordovês, são citados Lucano e Cícero, por diversas vezes, para sublinhar a ética, a justiça e a equidade. D. Henrique volta a citar Cícero na lin. 490, recuperando a ética e a honra dos antigos, em sintonia com o código de cavalaria: "a palavra deve ser mantida mesmo para com o inimigo" (fides etiam hosti seruanda est).

O autor recorre ao cursus uelox para fazer visualizar quer a angústia ou aflição das circunstâncias, quer o entusiasmo, ou quando acompanha actos de fala, sobretudo se se tratar, designadamente no caso do Infante D. Fernando, de instigar os seus companheiros ao cumprimento da doutrina e à perseverança na fé ou de os encorajar no âmago da peleja ${ }^{18}$. O cursus tardus sobressai nas circunstâncias que exigem prudência,

${ }^{18}$ E. g. lin. 423-424. 
ponderaçáo ${ }^{19}$, ou quando a situação se pauta pela seriedade, pela gravidade ${ }^{20}$.

Já o primeiro discurso de D. Fernando (lin. 416-446) é dos mais perfeitos, de acordo com as regras da retórica. No exordium, evidencia-se a captatio beneuolentiae, a par do tópico attentum parare. D. Fernando expóe a causa na narratio, não sem deixar de tecer largas graças e louvores à protecção divina que até então havia acompanhado o exército português. Prepara, assim, a afirmação posterior "Nec reor [...] Deum nos temptare licitum esse", que, em virtude da anterior exaltação do auxílio divino, já não pode ser interpretada como descrença na Divina Providência ou falta de fé por parte de D. Fernando. Depois, faz o levantamento objectivo da situação crítica em que os Portugueses se encontram. Segue-se a argumentatio, onde o autor desenvolve a defesa da sua posição (probatio). Faz a refutatio do discurso irrealista, resultante de uma fé excessiva na intervenção divina, não por falta de fé, mas antes por se reputar humildemente indigno dessa manifestação. Julgar o contrário seria, isso sim, pôr Deus à prova. Esta frase "Nec reor Deum nos temptare licitum esse" (lin. 438) é mais um caso em que o texto mais antigo provém de Dt 6.16, mas que os Cristãos conhecem melhor através do passo do NT, Mt 4.7, onde Cristo remete de forma directa para o texto do AT: "non temptabis Dominum Deum tuum". Este passo foi enquadrado no discurso de D. Fernando, quando ele faz a apologia da rendição

\footnotetext{
${ }^{19}$ E. g. lin. 475.

${ }^{20}$ E. g. lin. 348.
} 
perante as dificuldades e a inferioridade numérica dos Portugueses, já sem esperanças de salvação.

Finalmente, conclui o discurso com uma breve peroratio, preconizando a entrega de Ceuta em favor da salvação das almas dos seus companheiros de armas.

Alguns dos argumentos desenvolvidos nesta alocução do Infante Santo são retomados no discurso dos militares. Nas lin. 431-446 do primeiro discurso, o autor recorre a uma argumentação justificativa, típica da oratória judicial. Nestes passos, o autor expóe argumentos religiosos, com base nos quais desenvolve uma forte apologética que justificaria a rendição dos Lusitanos aos olhos de qualquer personalidade eclesiástica, incluindo o Papa.

No discurso seguinte (lin. 476-494), D. Henrique manifesta a sua discordância relativamente ao teor das argumentaçóes até aí desenvolvidas, renova a sua argumentação com motivos que ele julga irrecusáveis e incita as tropas à luta com entusiásticas palavras de encorajamento. É no âmbito desta divergência de opinióes entre o grosso das tropas lusas e o seu comandante, o Infante D. Henrique, que sobressaem as argumentaçôes e contra-argumentaçôes de uma e outra parte, acompanhadas de citaçóes de textos jurídicos. As posiçôes antagónicas são reforçadas por advérbios, conjunçôes, locuçóes, antonímia, combinaçóes vocabulares antitéticas, figuras de estilo... ${ }^{21}$

O estilo argumentativo é evidenciado através de conjunçốes que introduzem razões de direito, as

${ }^{21}$ E. g. non reuera..., immo uerius...; non..., sed...; aut..., aut...;... 
quais, por sua vez, impóem razóes de facto e levam a uma conclusão: quia, quoniam, ergo. $\mathrm{O}$ único registo de ergo ocorre na lin. 462, em plena argumentação de cunho vincadamente forense, onde se pesam os prós e os contras da decisão a tomar em função da ameaça das circunstâncias vigentes:

Os inflamados discursos do Martyrium et Gesta... apelam constantemente à qualidade de cavaleiros dos combatentes portugueses, cavaleiros com a responsabilidade acrescida da fé cristá que subjaz à sua condição de milites Christi. Mas o temporal e o espiritual colidem, quando se torna necessário decidir o futuro das hostes portuguesas.

D. Henrique apela à honra e dignidade de cavaleiro (lin. 446-452) - Amara siquidem nobis sistit fama, si ab istis diuincimur canibus ${ }^{22}$ - e, quando aduz argumentos baseados na fé cristâ, fá-lo para consolidar a defesa da honra de cavaleiro (lin. 476-494).

D. Fernando, que, por um lado, sempre demonstrara uma grande preocupação com o bem-estar físico e espiritual daqueles que thes haviam sido confiados e, por outro, punha tanto empenho na libertação dos cristáos cativos, jamais poderia aceitar a responsabilidade de criar uma situação de cativeiro para tanta gente, ele que tanto dinheiro gastara a remir cativos. A única solução possível e congruente com a sua perspectiva doutrinária, seria assumir ele próprio as consequências e carregar aos ombros o sofrimento dos seus correligionários.

22 "É, com efeito, amarga a fama que nos espera, se formos vencidos por estes cães". 
Já sabíamos que o amor paroxístico pelo Divino, pelo Transcendente, próprio de uma alma devota e piedosa, despertava no jovem Mestre de Avis um desejo intenso de seguir o Salvador até ao suplício supremo A imitação de Cristo por D. Fernando, tão típica do franciscanismo e da deuotio moderna, assume nas lin. 496-514 o seu expoente máximo com a entrega voluntária de D. Fernando como refém em prol da salvaçáo dos seus companheiros de armas e sobretudo de seu irmão, D. Henrique. O episódio começa com uma prelecção de $\mathrm{D}$. Fernando, que mais não é senão uma fundamentação explicativa do seu propósito.

Perante uma situação desesperada, de derrota iminente, qual a atitude mais correcta do cristáo: renderse às evidências e poupar a vida de seres humanos ou acreditar na vitória divina?

Como D. Fernando argumentou, um dos pecados capitais consistia em pôr à prova o próprio Deus. D. Fernando deseja evitar esse perigo, pois a vitória só poderia ser alcançada mediante uma intervenção divina directa: um milagre. Todavia, ao insistir na continuação do combate, a despeito de todas as contrariedades, D. Henrique nunca pensou em tentar a Deus. Pelo contrário, a sua atitude acusava uma fé inabalável no poder do Altíssimo, uma fé de fazer mover montanhas. A sua confiança é de tal modo absoluta que náo vacila perante as adversidades da realidade. D. Henrique encarna o ideal do miles Christi, o monge cavaleiro, onde o fervor religioso se objectiva num esto guerreiro ${ }^{23}$.

${ }^{23}$ Vd. Saraiva, José Hermano (1948), "Uma carta do Infante 
Isto não significa que D. Fernando tivesse menos fé que D. Henrique. Seria porventura mais realista, porque se julgaria indigno do socorro divino, sobretudo sob a forma de milagre. Além disso, D. Fernando pensava nos seus homens, nas respectivas famílias e principalmente no perigo de muita gente poder vir a abjurar a fé cristã no cativeiro. Preferia, como aconteceu, oferecer-se a si próprio em livramento de seus companheiros, a ser responsabilizado perante Deus pela perdição de tantas almas.

Embora os dois pontos de vista apontassem para decisóes completamente opostas, eram inteiramente coerentes com a vivência cristã e a dimensão espiritual de cada um dos príncipes de Avis. Nos dois irmãos, que dirigem a expedição, encontram-se, assim, conjugados os dois tipos de cavalaria: o cavaleiro e o monge, o temporal e o espiritual. Os dois Infantes complementam-se um ao outro, encarnando, assim, uma simbiose dos dois estados de espírito do cavaleiro de Cristo.

D. Henrique e o problema das causas da expansão portuguesa no norte de África”, Ethnos 3: 319-345, designadamente na p. 338, onde este erudito enquadra o carácter de D. Henrique na sua época: "Um dos mais curiosos aspectos em que se pode surpreender o estado de espírito do cavaleiro-cruzado são os frequentes milagres e prodígios com que, segundo eles crêem, Deus os distingue". Também no Martyrium et Gesta... D. Henrique acredita firmemente na iminência de um portento divino que permita superar a inferioridade numérica. 